\title{
Associations between maternal obesity and infectious morbidity in Zimbabwean infants
}

\author{
Thomas Althaus ${ }^{1} \cdot$ Bernard Chasekwa $^{2} \cdot$ Ruairi C. Robertson ${ }^{3} \cdot{\text { Robert Ntozini } \mathbb{C}^{2}}^{2} \cdot$ Katie Greenland ${ }^{1}$. \\ Jean H. Humphrey ${ }^{2,4}$. Andrew J. Prendergast $\mathbb{B}^{2,3,4}$
}

Received: 26 July 2020 / Revised: 28 February 2021 / Accepted: 18 March 2021 / Published online: 28 April 2021

(c) The Author(s) 2021. This article is published with open access

\begin{abstract}
The prevalence of overweight and obesity is increasing among reproductive-age women in sub-Saharan Africa. Whether maternal body mass index (BMI) influences the risk of infant infections in low- and middle-income countries (LMIC) is uncertain. We used data from a birth cohort of 5344 HIV-unexposed Zimbabwean infants with available data on maternal BMI, to calculate rates of sick clinic visits for infections during the first 12 months postpartum, and adjusted hazard ratios (aHR) for each maternal BMI group. Compared to infants of mothers with normal BMI, the rate of sick clinic visits for any infection progressively rose among infants of overweight (aHR 1.05; 95\%CI 0.99, 1.11) and obese women (aHR 1.15; 95\% CI 1.05, 1.25). Excess clinic attendances were particularly due to skin, respiratory and ear infections. Maternal obesity may therefore influence infant infectious morbidity in LMIC over the first year after birth.
\end{abstract}

\section{Introduction}

The prevalence of overweight and obesity in low- and middle-income countries (LMIC) has markedly increased over recent decades [1]. In contrast to high-income countries, overweight and obesity in sub-Saharan Africa are more common in women compared to men [1]. Obesity in reproductive-age women is associated with an elevated risk of neonatal, perinatal, and infant death, in both high-income and LMIC settings [2, 3]. However, few studies have examined the influence of maternal overweight and obesity on infant infectious morbidity.

Excess adiposity is associated with chronic inflammation and immune dysfunction [4], which is evident in the placenta and umbilical cord blood of obese mothers [5].

Supplementary information The online version contains supplementary material available at https://doi.org/10.1038/s41430021-00907-4.

Ruairi C. Robertson

r.robertson@qmul.ac.uk

$\triangle$ Andrew J. Prendergast

a.prendergast@qmul.ac.uk

1 London School of Hygiene and Tropical Medicine, London, UK
This altered immune phenotype observed in maternal obesity may plausibly shape offspring immune development and subsequent infection risk [6]. Indeed, large studies from high-income countries have observed that each unit increase in body-mass index (BMI) of mothers during early pregnancy is associated with an $8.3 \%$ increased risk of earlyonset sepsis in term infants [7]. Similarly, maternal obesity is associated with a higher risk of infant respiratory tract infections during the first year of life [8]. Longer-term follow-up studies have also shown that maternal overweight or obesity are independent risk factors for hospitalization for infections in children up to 5 years [9] and 18 years [10] of age.

Existing evidence is almost exclusively from highincome settings, while the burden of infectious diseases in children is far greater in LMIC. Here, we investigate associations between maternal overweight and obesity and infant infectious morbidity in a Zimbabwean birth cohort.

2 Zvitambo Institute for Maternal and Child Health Research, Harare, Zimbabwe

Blizard Institute, Queen Mary University of London, London, UK

4 Department of International Health, Johns Hopkins Bloomberg School of Public Health, Baltimore, MD, USA 


\section{Methods}

This study used data from the ZVITAMBO trial [11]. Briefly, 14,110 mother-infant pairs were enrolled after delivery in Harare, Zimbabwe between 1997 and 2000. Mother-infant pairs were eligible if neither had acutely lifethreatening conditions, the baby was a singleton with a birthweight $>1500 \mathrm{~g}$, and the mother planned to stay in Harare. Maternal written informed consent was obtained. The Medical Research Council of Zimbabwe, Institutional Review Board of Johns Hopkins Bloomberg School of Public Health, USA, and Montreal General Hospital, Canada, provided approvals. The trial was registered at clinicaltrials.gov (NCT00198718).

In this analysis, we included HIV-negative mothers with available anthropometry. Height was measured at delivery, and weight at 6-weeks postpartum. Maternal BMI was classified as underweight $\left(<18.5 \mathrm{~kg} / \mathrm{m}^{2}\right)$; normal $\left(18.5-24.99 \mathrm{~kg} / \mathrm{m}^{2}\right)$; overweight $\left(25-29.99 \mathrm{~kg} / \mathrm{m}^{2}\right)$; or obese $\left(\geq 30 \mathrm{~kg} / \mathrm{m}^{2}\right)$. At 6 weeks, then 3, 6, 9, and 12 months of age, mothers were asked whether their infant had attended a clinic, hospital, outpatient department, casualty, private doctor, or nurse since the previous study visit. The date and reason for each visit were determined from handheld records or, if these were not available, by maternal report. If a child was sick during a scheduled study visit, or if a sick child presented to the research clinic between scheduled visits, free treatment was provided and study staff recorded the reason for the visit. We were interested in all infant infections, which we classified as acute respiratory infection (ARI), tuberculosis, diarrhea, dysentery, ear infection, fever, lymphadenopathy, measles, other skin rashes, malaria, oral thrush, and "other" infection. Each reported visit for these illnesses contributed to the calculated rate of clinic visits for "any infection". Rates of attendance for specific infections were calculated for the most common causes: ARI, diarrhea (including dysentery), ear infections, skin rash (including measles), and fever; other categories had too few events to calculate infection-specific visits rates.

The number of clinic visits was compared between maternal BMI groups, and rates per 1000 child-months calculated. An exponential regression model with gamma frailty was used to obtain unadjusted and adjusted hazard ratios (aHR) for each group, using normal BMI as the reference group. We considered all variables associated with maternal BMI and the outcome of interest as potential confounders. We tested each variable individually and included those affecting the point estimates of the outcomes or their $95 \%$ confidence intervals. Covariates selected for the final models were gestational age, birth weight, parity, maternal education, and household income. Analysis was undertaken using STATA version 12 (College Station, Texas, USA).

\section{Results}

Among 14,110 women, 9208 (65.3\%) were HIV-negative; of these, $5344(58.0 \%)$ had BMI data available and were included in this analysis. Supplementary Table 1 shows the differences between women with and without BMI data. Overall, $240(4.5 \%)$ women were underweight; 3552 (66.5\%) had normal BMI; 1171 (21.9\%) were overweight and $381(7.1 \%)$ were obese. Table 1 shows the baseline characteristics of mothers and infants.

Table 2 shows the rates of clinic attendances during infancy and aHRs for each maternal BMI category. The rate of clinic visits for any infection progressively rose with increasing BMI categories. In adjusted analyses, clinic attendance for any infection tended to be higher among infants of overweight women (aHR 1.05; 95\%CI 0.99, 1.11) and was significantly higher among infants of obese women (aHR 1.15; 95\%CI 1.05, 1.25). There was no evidence of increased clinic attendance among infants of underweight mothers.

Infants born to obese compared to normal-weight mothers had a significantly higher rate of clinic attendance for skin rash (aHR $1.46(95 \% \mathrm{CI} 1.17,1.82))$, and some evidence of increased clinic attendance for ARI (aHR $1.09 ; 95 \%$ CI $0.98,1.22$ ). Infants of overweight compared to normal-weight mothers had a significantly higher rate of clinic attendance for ear infections (aHR 1.30; 95\% CI $1.01,1.66)$.

\section{Discussion}

Here, we report that maternal BMI is associated with infant infectious morbidity in the first year of life in a Zimbabwean birth cohort. Specifically, infants of overweight and obese mothers had more clinic attendances for infections compared to infants of mothers with normal BMI, particularly for skin, ear, and respiratory infections.

Maternal overweight and obesity have previously been associated with stillbirth, fetal death, and preterm birth, in studies conducted predominantly in high-income countries $[2,12]$. In the neonatal period, the risk of early-onset sepsis and mortality are also elevated in the offspring of overweight and obese mothers $[2,7,13]$. In an analysis of data from 27 sub-Saharan African countries, maternal obesity was associated with increased odds of neonatal death (adjusted odds ratio 1.46, 95\%CI 1.11-1.91), with infections likely to be one of the underlying causes [3]. The longer-term influence of maternal BMI on health in childhood is more difficult to delineate due to the influence of other confounding factors [6]. However, previous studies from high-income settings have reported more hospitalizations for infectious diseases in children born to obese 
Table 1 Baseline characteristics of infants and mothers.

\begin{tabular}{|c|c|c|c|c|c|}
\hline & \multicolumn{4}{|l|}{ Maternal BMI } & \multirow[t]{2}{*}{$P$-value } \\
\hline & $\begin{array}{l}\text { Underweight } \\
(n=240)\end{array}$ & $\begin{array}{l}\text { Normal } \\
(n=3552)\end{array}$ & $\begin{array}{l}\text { Overweight } \\
(n=1171)\end{array}$ & $\begin{array}{l}\text { Obese } \\
(n=381)\end{array}$ & \\
\hline \multicolumn{6}{|l|}{ Infant characteristics } \\
\hline Male sex, $n(\%)$ & $129(53.7)$ & $1844(51.9)$ & $602(51.4)$ & $195(51.3)$ & 0.900 \\
\hline Gestational age, weeks, mean (SD) & $39.0(1.5)$ & $39.3(1.4)$ & $39.4(1.3)$ & $39.6(1.4)$ & 0.060 \\
\hline Preterm (<37 weeks), $n(\%)$ & $30(12.5)$ & $220(6.2)^{\mathrm{a}}$ & $63(5.4)^{\mathrm{a}}$ & $18(4.7)^{\mathrm{a}}$ & 0.006 \\
\hline Apgar score, median (IQR) & $10(9-10)$ & $10(9-10)$ & $10(9-10)$ & $10(9-10)$ & 0.250 \\
\hline Feeding pattern, $n(\%):^{2}$ & & & & & 0.447 \\
\hline - Exclusive breastfeeding & $13(5.4)$ & $186(5.2)$ & $63(5.4)$ & $31(8.1)$ & \\
\hline - Predominant breastfeeding & $44(18.3)$ & 768 (21.6) & $261(22.3)$ & $81(21.3)$ & \\
\hline - Mixed breastfeeding & $128(53.3)$ & $1,892(53.3)$ & $636(54.3)$ & $205(53.8)$ & \\
\hline Birth length, cm, mean (SD) & $47.9(2.4)$ & $48.5(2.6)$ & $48.9(2.5)^{\mathrm{a}}$ & $49.2(2.5)^{\mathrm{a}}$ & $<0.001$ \\
\hline Birth weight, grams, mean (SD) & $2819(431)$ & $2979(435)^{\mathrm{a}}$ & $3109(440)^{\mathrm{a}, \mathrm{b}}$ & $3181(490)^{\mathrm{a}, \mathrm{b}}$ & 0.010 \\
\hline Infant Vitamin $\mathrm{A}, n(\%)^{3}$ & $130(54.2)$ & $1725(48.6)$ & $608(51.9)$ & $194(50.9)$ & 0.100 \\
\hline \multicolumn{6}{|l|}{ Maternal characteristics } \\
\hline Age, years, median (IQR) & $21.5(19.2-24.4)$ & $22.5(20.0-25.9)^{\mathrm{a}}$ & $24.9(21.4-29.6)^{\mathrm{a}, \mathrm{b}}$ & $28.5(24.1-34.3)^{\mathrm{a}, \mathrm{b}, \mathrm{c}}$ & $<0.001$ \\
\hline Parity, median (IQR) & $1(1-2)$ & $1(1-2)^{\mathrm{a}}$ & $2(1-3)^{\mathrm{a}, \mathrm{b}}$ & $3(2-4)^{a, b, c}$ & $<0.001$ \\
\hline Weight, $\mathrm{kg}$, mean $(\mathrm{SD})^{4}$ & $46.8(5.2)$ & $56.4(6.2)^{\mathrm{a}}$ & $68.5(5.9)^{\mathrm{a}, \mathrm{b}}$ & $84.7(9.2)^{\mathrm{a}, \mathrm{b}, \mathrm{c}}$ & $<0.001$ \\
\hline Height, cm, mean (SD) & $162.7(8.9)$ & $160.2(6.4)^{\mathrm{a}}$ & $159.4(5.9)^{\mathrm{a}, \mathrm{b}}$ & $159.7(6.1)^{\mathrm{a}}$ & $<0.001$ \\
\hline MUAC, cm, mean (SD) & $23.1(2.0)$ & $25.1(2.2)^{\mathrm{a}}$ & $28.2(2.3)^{\mathrm{a}, \mathrm{b}}$ & $29.4(4.4)^{\mathrm{a}, \mathrm{b}, \mathrm{c}}$ & $<0.001$ \\
\hline Married or stable union, $n(\%)$ & $222(92.5)$ & 3351 (94.3) & 1107 (94.5) & $369(96.9)^{a, b}$ & 0.005 \\
\hline Education: secondary, $n(\%)$ & $205(85.4)$ & $3019(85.0)$ & $964(82.3)$ & $271(71.1)^{\mathrm{a}, \mathrm{b}, \mathrm{c}}$ & $<0.001$ \\
\hline Employed, $n(\%)$ & $21(8.8)$ & $319(9.0)$ & $154(13.2)^{\mathrm{a}, \mathrm{b}}$ & $70(18.4)^{\mathrm{a}, \mathrm{b}}$ & $<0.001$ \\
\hline Household income/month, US\$, median (IQR) & $963(650-1612)$ & $1056(700-1738)$ & $1186(780-1974)^{\mathrm{a}, \mathrm{b}}$ & $1468(949-2426)^{a, b, c}$ & $<0.001$ \\
\hline Husband secondary education, $n(\%)$ & $229(95.4)$ & $3294(92.7)$ & $1076(91.9)$ & $312(81.9)^{\mathrm{a}, \mathrm{b}, \mathrm{c}}$ & $<0.001$ \\
\hline Husband employment, $n(\%)$ & $150(62.5)$ & $2068(58.2)$ & $715(61.1)$ & $242(63.5)$ & 0.29 \\
\hline
\end{tabular}

${ }^{1} \mathrm{P}$ values were calculated using the chi-squared test for binary variables, ANOVA for comparison of means, and Kruskall-Wallis tests for comparison of medians. A post-hoc Bonferroni test was conducted if overall $p$-value $<0.05$; the superscript letter denotes a significant difference between that group and ${ }^{\mathrm{a}}$ underweight, ${ }^{\mathrm{b}}$ normal weight, ${ }^{\mathrm{c}}$ overweight, and ${ }^{\mathrm{d}}$ obese.

${ }^{2}$ Detailed feeding information was collected from mothers at 6 weeks, 3 months, and 6 months of age, including whether any of 22 liquids (water, juice, tea, cooking oil), milk (formula, fresh, tinned), medicines (traditional, oral rehydration solution, prescribed) or solid foods (porridge, sadza, fruit, vegetables, meat, eggs) had been given to the infant. Breastfeeding was defined as exclusive, predominant, or mixed at 3 months of age. Data were not available at 3 months of age for $23 \%$ underweight, $15 \%$ normal BMI, $18 \%$ overweight, and $17 \%$ obese women.

${ }^{3}$ The randomization in the original ZVITAMBO trial, to $\mathrm{Aa}, \mathrm{Pa}, \mathrm{Ap}$, and $\mathrm{Pp}$ (where $\mathrm{A}$ is maternal Vitamin $\mathrm{A}, \mathrm{P}$ is maternal placebo, a is infant Vitamin A and $\mathrm{p}$ is infant placebo).

${ }^{4}$ Maternal weight was measured 6 weeks postpartum.

mothers during follow-up through 18 years of age [9, 10, 14]. Maternal-reported wheeze, prolonged cough, and lower respiratory tract infections (but not croup, ear infections, diarrhea, or vomiting) among infants were associated with higher maternal BMI in a UK study [8].

Data on infectious morbidity from LMIC are lacking, despite the high burden of disease. In 2016, lower respiratory tract infections caused over 650,000 deaths in children under-five worldwide [15], and diarrhea was the fifth leading cause of death [16]. During the ongoing "nutrition transition", when maternal overweight and obesity are increasing in LMIC, it is critical to identify early-life risk factors for childhood infection. We believe this is the first study reporting an association between maternal BMI and infant infections in LMIC.

Despite observational data supporting an association between maternal BMI and childhood infection in highincome settings, the underlying mechanisms are poorly understood. Obesity prior to and during pregnancy is associated with maternal immune deficits including reduced natural-killer cells and CD8 + T-cells [17, 18]. Consequently, infants born to obese mothers have fewer eosinophils and CD4 T-cells, and impaired responses to stimulation from toll-like receptor ligands, suggesting that 
Table 2 Clinic visits for infections during the first year after birth by maternal BMI category.

\begin{tabular}{|c|c|c|c|c|}
\hline Type of infection & Number of visits ${ }^{\mathrm{a}}$ & $\begin{array}{l}\text { Rate/1000 child- } \\
\text { months }\end{array}$ & Crude hazard ratio & Adjusted hazard ratiob \\
\hline \multicolumn{5}{|l|}{ Any infection ${ }^{\mathrm{c}}$} \\
\hline Underweight & 485 & 168.4 & $0.98(0.88-1.08)$ & $1.01(0.90-1.14)$ \\
\hline Normal & 7323 & 172.3 & 1 & 1 \\
\hline Overweight & 2499 & 178.2 & $1.03(0.98-1.09)$ & $1.05(0.99-1.11)$ \\
\hline Obese & 878 & 193.8 & $1.13(1.04-1.22)$ & $1.15(1.05-1.25)$ \\
\hline \multicolumn{5}{|l|}{ Diarrhea $^{\mathrm{d}}$} \\
\hline Underweight & 70 & 24.3 & $1.19(0.91-1.55)$ & $1.30(0.95-1.76)$ \\
\hline Normal & 874 & 20.5 & 1 & 1 \\
\hline Overweight & 265 & 18.9 & $0.92(0.79-1.07)$ & $0.96(0.81-1.13)$ \\
\hline Obese & 96 & 21.1 & $1.03(0.82-1.29)$ & $1.12(0.86-1.46)$ \\
\hline \multicolumn{5}{|l|}{$A R I$} \\
\hline Underweight & 288 & 100 & $0.90(0.79-1.03)$ & $0.96(0.82-1.11)$ \\
\hline Normal & 4706 & 110.6 & 1 & 1 \\
\hline Overweight & 1539 & 109.7 & $0.99(0.93-1.06)$ & $0.99(0.92-1.06)$ \\
\hline Obese & 553 & 121.4 & $1.10(1.00-1.21)$ & $1.09(0.98-1.22)$ \\
\hline \multicolumn{5}{|l|}{ Fever } \\
\hline Underweight & 43 & 14.9 & $1.06(0.76-1.47)$ & $0.86(0.56-1.32)$ \\
\hline Normal & 602 & 14.2 & 1 & 1 \\
\hline Overweight & 195 & 13.9 & $0.98(0.83-1.17)$ & $1.00(0.82-1.21)$ \\
\hline Obese & 78 & 17.1 & $1.21(0.94-1.56)$ & $1.10(0.82-1.48)$ \\
\hline \multicolumn{5}{|l|}{ Ear infection } \\
\hline Underweight & 15 & 5.2 & $0.71(0.39-1.28)$ & $0.93(0.48-1.83)$ \\
\hline Normal & 314 & 7.4 & 1 & 1 \\
\hline Overweight & 134 & 9.5 & $1.30(1.01-1.66)$ & $1.41(1.05-1.89)$ \\
\hline Obese & 45 & 9.9 & $1.34(0.90-1.99)$ & $1.20(0.74-1.93)$ \\
\hline \multicolumn{5}{|l|}{ Skin infection ${ }^{\mathrm{e}}$} \\
\hline Underweight & 80 & 27.8 & $1.00(0.76-1.29)$ & $0.90(0.65-1.24)$ \\
\hline Normal & 1196 & 28.1 & 1 & 1 \\
\hline Overweight & 432 & 30.8 & $1.10(0.96-1.25)$ & $1.09(0.94-1.27)$ \\
\hline Obese & 169 & 37.2 & $1.32(1.09-1.61)$ & $1.46(1.17-1.82)$ \\
\hline
\end{tabular}

ARI Acute respiratory infection.

${ }^{a}$ Number of visits between birth and 12 months of age are calculated among 240 children born to underweight mothers; 3552 born to mothers in normal BMI range; 1171 born to overweight mothers, and 381 born to obese mothers.

${ }^{\mathrm{b}}$ Adjusted hazard ratios were calculated using gestational age, birth weight, maternal education, income, and parity as covariates.

${ }^{c}$ Acute respiratory infection, tuberculosis, acute and persistent diarrhea, dysentery, ear infection, fever, lymphadenopathy, measles, other skin rashes, malaria, oral thrush, and other infection.

${ }^{\mathrm{d}}$ Including dysentery.

${ }^{\mathrm{e}}$ Measles and other skin rashes. maternal BMI influences neonatal immune ontogeny $[5,19]$. Neonates of overweight and obese mothers also display increased "inflammatory scores" characterized by elevated pro-inflammatory and reduced anti-inflammatory biomarkers [20]. This altered immune landscape in infants of obese mothers may influence early-life infection susceptibility. Obesity also increases the risk of maternal infections $[21,22]$. This may enable vertical transmission of pathogens to the offspring and thereby increase the risk of infant infection [23]. An alternative explanation is that overweight and obese mothers had different health-seeking behaviors. Mothers with greater BMI had higher household income in our study, which is associated with better access to healthcare [24]; however, the elevated risk of infections remained after adjusting for income and education. 
Our results are strengthened by the large cohort and regular postnatal follow-up. In addition, free clinical care during the trial and review of medical records from clinic attendances allowed the collection of robust data on infant illnesses. However, there are also limitations. First, data on maternal BMI were missing for $41.7 \%$ of eligible mothers from the trial population, who differed in several respects. Excluded women were younger, with lower parity, midupper arm circumference, and infant birth weight, and differences in breastfeeding; all these factors could influence infant infectious morbidity. Second, BMI was measured 6weeks postpartum, which may not reflect pre-pregnancy weight or gestational weight gain. Third, clinic visits for specific symptoms such as diarrhea and skin rash were assumed to indicate infections, but some episodes may have been due to non-infectious causes. Finally, although we adjusted our models for gestational age, birth weight, parity, maternal education, and household income, there may still be unmeasured confounding which explains the associations reported.

In summary, we report that overweight and obesity in Zimbabwean women are associated with more clinic attendances for infant infections during the first year after birth. Whether these findings are predominantly driven by altered infant immune development, increased pathogen transmission, or differences in health-seeking behavior requires further investigation. Regardless of the underlying causes, our results highlight the potential impact of maternal obesity on the health of infants beyond the newborn period. Given the increasing prevalence of obesity in LMIC, especially among reproductive-age women, there may be increased pressure on resource-limited health systems due to effects on infant health. Further studies evaluating the influence of maternal overweight and obesity on infant morbidity, mortality, growth, and development in LMIC are required.

Author contributions Study concept and design: TA, BC, RCR, BC, $\mathrm{KG}, \mathrm{JHH}, \mathrm{AJP}$. Data analysis: TA, KG, BC, RN. Wrote the manuscript: TA, RCR, AJP. Critically revised manuscript: KG, BC, RN, JHH. Obtained trial funding: JHH. Trial oversight and conduct: JHH.

Funding This work was supported by the Wellcome Trust [108065/Z/ 15/Z to AJP; and 206455/Z/17/Z to RCR]. The ZVITAMBO trial was supported by the Canadian International Development Agency (CIDA) (R/C Project 690/M3688), United States Agency for International Development (USAID) (cooperative agreement number HRN-A-0097-00015-00 between Johns Hopkins University and the Office of Health and Nutrition-USAID) and a grant from the Bill and Melinda Gates Foundation, Seattle WA. Additional funding was received from the SARA Project, which is operated by the Academy for Educational Development, Washington DC, and is funded by the USAID Bureau for Africa, Office of Sustainable Development under the terms of Contract AOT-C-00-99-00237-00, the Rockefeller Foundation (NY, NY) and BASF (Ludwigshafen, Germany).

\section{Compliance with ethical standards}

Conflict of interest The authors declare no competing interests.

Publisher's note Springer Nature remains neutral with regard to jurisdictional claims in published maps and institutional affiliations.

Open Access This article is licensed under a Creative Commons Attribution 4.0 International License, which permits use, sharing, adaptation, distribution and reproduction in any medium or format, as long as you give appropriate credit to the original author(s) and the source, provide a link to the Creative Commons license, and indicate if changes were made. The images or other third party material in this article are included in the article's Creative Commons license, unless indicated otherwise in a credit line to the material. If material is not included in the article's Creative Commons license and your intended use is not permitted by statutory regulation or exceeds the permitted use, you will need to obtain permission directly from the copyright holder. To view a copy of this license, visit http://creativecommons. org/licenses/by/4.0/.

\section{References}

1. NCD Risk Factor Collaboration (NCD-RisC). Worldwide trends in body-mass index, underweight, overweight, and obesity from 1975 to 2016: a pooled analysis of 2416 population-based measurement studies in 128.9 million children, adolescents, and adults. Lancet. 2017;390:2627-42.

2. Aune D, Saugstad OD, Henriksen T, Tonstad S. Maternal body mass index and the risk of fetal death, stillbirth, and infant death: a systematic review and meta-analysis. JAMA. 2014;311:1536-46.

3. Cresswell JA, Campbell OM, De Silva MJ, Filippi V. Effect of maternal obesity on neonatal death in sub-Saharan Africa: multivariable analysis of 27 national datasets. Lancet. 2012; 380:1325-30.

4. Huttunen R, Syrjänen J. Obesity and the risk and outcome of infection. Int J Obes. 2013;37:333-40.

5. Wilson RM, Marshall NE, Jeske DR, Purnell JQ, Thornburg K, Messaoudi I. Maternal obesity alters immune cell frequencies and responses in umbilical cord blood samples. Pediatr Allergy Immunol. 2015;26:344-51.

6. Godfrey KM, Reynolds RM, Prescott SL, Nyirenda M, Jaddoe VW, Eriksson JG, et al. Influence of maternal obesity on the longterm health of offspring. Lancet Diabetes Endocrinol. 2017; 5:53-64.

7. Villamor E, Norman M, Johansson S, Cnattingius S. Maternal Obesity and Risk of Early-onset Neonatal Bacterial Sepsis: Nationwide Cohort and Sibling-controlled Studies. Clin Infect Dis. 2020; ciaa783. https://doi.org/10.1093/cid/ciaa783.

8. Rajappan A, Pearce A, Inskip HM, Baird J, Crozier SR, Cooper C, et al. Maternal body mass index: Relation with infant respiratory symptoms and infections. Pediatr Pulmonol. 2017;52:1291-9.

9. Videholm S, Silfverdal SA, Reniers G. Maternal weight and infections in early childhood: a cohort study. Arch Dis Child. 2019;104:58-63.

10. Gutvirtz G, Wainstock T, Landau D, Sheiner E. Maternal obesity and offspring long-term infectious morbidity. J Clin Med. 2019;8:1466

11. Humphrey JH, Iliff PJ, Marinda ET, Mutasa K, Moulton LH, Chidawanyika $\mathrm{H}$, et al. Effects of a single large dose of vitamin A, given during the postpartum period to HIV-positive women and their infants, on child HIV infection, HIV-free survival, and mortality. J Infect Dis. 2006;193:860-71. 
12. McDonald SD, Han Z, Mulla S, Beyene J, Group KS. Overweight and obesity in mothers and risk of preterm birth and low birth weight infants: systematic review and meta-analyses. BMJ. 2010;341:c3428.

13. Rastogi S, Rojas M, Rastogi D, Haberman S. Neonatal morbidities among full-term infants born to obese mothers. J Matern Fetal Neonatal Med. 2015;28:829-35.

14. Cameron CM, Shibl R, McClure RJ, Ng SK, Hills AP. Maternal pregravid body mass index and child hospital admissions in the first 5 years of life: results from an Australian birth cohort. Int $\mathbf{J}$ Obes. 2014;38:1268-74.

15. Collaborators GLRI. Estimates of the global, regional, and national morbidity, mortality, and aetiologies of lower respiratory infections in 195 countries, 1990-2016: a systematic analysis for the Global Burden of Disease Study 2016. Lancet Infect Dis. 2018;18:1191-210

16. GBD 2016 Diarrhoeal Disease Collaborators. Estimates of the global, regional, and national morbidity, mortality, and aetiologies of diarrhoea in 195 countries: a systematic analysis for the Global Burden of Disease Study 2016. Lancet Infect Dis. 2018; 18:1211-28.

17. Sen S, Iyer C, Klebenov D, Histed A, Aviles JA, Meydani SN. Obesity impairs cell-mediated immunity during the second trimester of pregnancy. Am J Obstet Gynecol. 2013; 208:139.e1-8.
18. Sureshchandra S, Marshall NE, Wilson RM, Barr T, Rais M, Purnell JQ, et al. Inflammatory determinants of pregravid obesity in placenta and peripheral blood. Front Physiol. 2018;9:1089.

19. Wilson RM, Messaoudi I. The impact of maternal obesity during pregnancy on offspring immunity. Mol Cell Endocrinol. 2015; 418:134-42.

20. Broadney MM, Chahal N, Michels KA, McLain AC, Ghassabian A, Lawrence DA, et al. Impact of parental obesity on neonatal markers of inflammation and immune response. Int $\mathrm{J}$ Obes. 2017;41:30-7.

21. Heslehurst N, Simpson H, Ells LJ, Rankin J, Wilkinson J, Lang R, et al. The impact of maternal BMI status on pregnancy outcomes with immediate short-term obstetric resource implications: a metaanalysis. Obes Rev. 2008;9:635-83.

22. Kleweis SM, Cahill AG, Odibo AO, Tuuli MG. Maternal obesity and rectovaginal group b streptococcus colonization at term. Infect Dis Obstet Gynecol. 2015;2015:586767.

23. Chan GJ, Lee AC, Baqui AH, Tan J, Black RE. Prevalence of early-onset neonatal infection among newborns of mothers with bacterial infection or colonization: a systematic review and metaanalysis. BMC Infect Dis. 2015;15:118.

24. Kevany S, Murima O, Singh B, Hlubinka D, Kulich M, Morin SF, et al. Socio-economic status and health care utilization in rural Zimbabwe: findings from Project Accept (HPTN 043). J Public Health Afr. 2012;3:46-51. 